\title{
Una mirada alternativa a las experiencias de vida en torno a los procesos de salud-enfermedad
}

\author{
Reseña de: Martínez Vilchis, José y Gabriel G. Huitrón Bravo \\ (COMPS.) (2001), SALUd y SOCIEDAD. Sus mÉtodos CUalitativos DE \\ inVESTIGACIÓN, Universidad AutónOMA del Estado de MÉXico, \\ Toluca, MÉXICO, 132 Pp.
}

Hace aproximadamente dos décadas, en las ciencias sociales se ha puesto atención a problemas sociales en torno a procesos de salud-enfermedad desde perspectivas de enfoques cualitativos de investigación con la finalidad de rescatar la experiencia de los propios sujetos (pacientes, familiares, enfermeras, trabajadoras sociales, médicos, etcétera) en dichos procesos y como expresión de su contexto sociocultural. El marco en el que se mira a dichos sujetos es el abandono paulatino de éstos por parte de los sistemas de salud, cuya tendencia ha sido desde entonces su privatización a partir de la puesta en marcha del modelo neoliberal.

También paulatinamente se ha fortalecido la experiencia de rescatar el trabajo que presentan los investigadores (ponentes) en ciclos de conferencias, congresos, coloquios, encuentros, etcétera, ya no sólo con la finalidad de elaborar memorias, sino para editarlos en libros. El libro Salud y sociedad. Sus métodos cualitativos de investigación es un ejemplo de ese tipo de trabajos, ya que es resultado del ciclo de conferencias "Salud y sociedad: sus métodos cualitativos de investigación" que organizaron las Facultades de Medicina y de Ciencias Políticas y Administración Pública de la Universidad Autónoma del Estado de México y que tuvo lugar los días 26, 27 y 28 de abril de 1999, donde participaron investigadores de diversas universidades del país.

Un ejercicio como el que se menciona es interesante porque convoca a la interdisciplinariedad a través de la cual conversan disciplinas científicas que antaño parecían no tener temas en común, ya que los problemas en torno a procesos de salud-enfermedad se pensaban como propios de la medicina o bien de estudios de carácter estructural en los que las estadísticas de cobertura en los servicios de salud, las cifras de morbilidad y de mortalidad parecían decir todo; sin embargo, entre lo que se desprende del libro aquí reseñado, las aportaciones de los enfoques cualitativos 
que miran más allá de las cifras y de las estructuras tienen mucho que decir.

Considero que ese tipo de trabajos permiten señalar que no se puede pasar por alto, por ejemplo, que actualmente muchos seres humanos viven con algún tipo de dolor-enfermedad (reumatismo, cáncer, Sida, afecciones neurológicas) (Rubinstein, 1990) a quienes la medicina y los servicios de salud no han logrado ofrecerles posibilidades de curación, ni alternativas suficientes para aliviar el dolor; por lo que todos de una u otra manera tienen que enfrentar su situación desde el momento que aparecen los síntomas.

Por ejemplo, según la Organización Mundial de la Salud (OMS), las enfermedades reumáticas constituyen una plaga social, y se sabe que un tercio de los franceses se quejan de reumatismo y representa en importancia la segunda causa de consulta médica; también a causa de los dolores lumbares se registra en ese país una pérdida de casi veinte millones de jornadas laborales al año (Rubinstein, 1990: 102). El Sida se ha convertido en una pandemia en el mundo: en Estados Unidos cada año mueren 16 mil personas a causa de dicha enfermedad y se estima que entre 800 mil o 900 mil personas están infectadas del virus del viH, de los cuales una tercera parte desconocen su condición y permanecen sin tratamiento (Kübler-Ross, 2002: 10).

Pero, más allá de las cifras, es importante que las ciencias sociales rescaten la experiencia de los sujetos en esos procesos de construcción y reconstrucción de su vida cotidiana, donde se pone en juego la salud y se enfrenta la enfermedad. Por lo que textos como el que aquí se reseña adquieren relevancia, ya que aportan otras lecturas de esas realidades.

El libro Salud y sociedad. Sus métodos cualitativos de investigación se integra con la compilación de siete ensayos que abordan, desde la perspectiva cualitativa, diversos temas en torno a la salud; como parte de la aproximación cualitativa, los trabajos se acercan a los espacios de la vida cotidiana como fuente válida de conocimiento, con lo que abren nuevas vetas para el proceso de investigación en torno a los proceso de salud-enfermedad.

Por ser una compilación de textos, resulta interesante brindar un panorama de cada uno de ellos, en los que se plasma la perspectiva personal de los autores como parte de su ejercicio de construcción e interpretación en su trabajo de investigación. 
El trabajo de Yólotl González Torres se titula: "Culpa y sociedad. La culpa como causa del pecado", donde la autora expone cómo en algunas civilizaciones, pueblos o comunidades rurales se construyen desde el ámbito cultural una serie de creencias y mitos que explican como causas de enfermedad el origen sobrenatural, por el rompimiento de algún tabú o por violar alguna regla moral. Se resalta entre los mitos la idea de que haber cometido pecado causa sentimiento de culpa y la culpa conlleva a la enfermedad. El trabajo hace referencia a diversos ejemplos de la sociedad mexicana en donde se registraba, desde la época de la colonia y aún en el presente ese tipo de creencias. Este es un ejemplo de trabajos en los cuales interesa comprender cómo los sujetos construyen algunos significados en torno a los procesos de enfermedad que padecen.

"La experiencia de la clínica mental durante el porfiriato" es otro de los textos que integran la compilación, en el que su autora, Martha Lilia Mancilla Villa, pretende "incursionar entre los hilos que entretejieron la vida de los enfermos mentales recluidos, entre 1880 y 1910 " en hospitales para dementes que darían paso al Manicomio General de La Castañeda, inaugurado por Porfirio Díaz en septiembre de 1910. Uno de los 'hilos' que la autora identifica como importantes en la vida de los enfermos mentales de dicha época fue la práctica clínica de los médicos alienistas (desde finales del siglo XVIII así se denominaba a los médicos especializados en el tratamiento de las alienaciones o enajenaciones mentales, y hasta finales del siglo XIX se conocieron como psiquiatras). Por lo anterior, la autora considera que la historia elaborada por el médico a partir de la observación e interpretación sobre el caso de cada paciente constituye la fuente de información directa del pensamiento médico ligado a su práctica clínica, a través de la cual se buscaba las causas de la enajenación mental en los antecedentes familiares, en las costumbres o en procesos de degeneración congénita de los pacientes. En el trabajo mencionado se aprecia que la autora exploró y encontró en los archivos de las historias clínicas de dichos pacientes una fuente de información que sistematizó para realizar la interpretación desde su perspectiva de análisis. Ejercicios como este ahora son válidos en las ciencias sociales, ya que van más allá de la perspectiva tradicional de la ciencia, en donde no había lugar para la interpretación. 
Carlos Garma Navarro es autor del texto "El trabajo de campo con iglesias pentecostales", y hace referencia a algunas experiencias en torno al trabajo de campo entre diversas iglesias de Iztapalapa. El autor centra su atención en las agrupaciones de pentecostales que se encontraban en la Delegación Iztapalapa del Distrito Federal durante el tiempo de estudio: 1989-1998, y analiza a esta congregación de creyentes en interacción con otras iglesias, con lo que muestra una realidad multiforme del trabajo de campo. A la vez esboza el contenido de su libro producto del mencionado trabajo de campo. En realidad, el autor introduce a la lectura de su texto, producto de un trabajo de más de diez años. En textos como este se pueden encontrar elementos interesantes que permiten comprender el papel que juega la religión en la construcción de significados en torno a procesos de salud-enfermedad, y rescatar las diferencias socioculturales que a partir de la religión van construyendo los sujetos, ya que no es la misma percepción sobre la enfermedad la de un católico que la de un testigo de Jehová o un cristiano, por ejemplo.

"La muerte y la eutanasia" es el título del trabajo de Juan María Parent. A partir de algunos planteamientos hechos por la fenomenología y posteriormente por el existencialismo francés, el autor expone una serie de reflexiones en torno a la muerte como un misterio que implica al ser humano y determinan en cada momento la significación de lo que hace. También reflexiona sobre la eutanasia como encuentro con la muerte provocada por otra persona o por un médico, a petición del paciente. Otras reflexiones giran en torno a la agatanasia o "mejor muerte", que se apoya en acto de doble efecto: un primer efecto es la disminución del dolor y un segundo efecto es la disminución del tiempo de vida. Trabajos como este siempre resultan polémicos, ya que están en estrecha relación con cuestiones de ética y otros valores sobre la vida, por lo que revisarlos implica la realización de una lectura desde ángulos eminentemente subjetivos, como son los de la vida humana.

El trabajo "Sociología cualitativa y salud. La vida detrás de las estadísticas”, cuya autora es Norma González González, expone diversas reflexiones en torno a lo que el conocimiento cualitativo de la sociedad puede aportar en el campo específico de los problemas de salud. Dichas reflexiones son expuestas en un apartado del texto titulado: La sociología cualitativa y la salud, en donde lo cualitativo se considera como el conocimiento de lo inmediato, de lo "irrelevante", esto es la microsociología como 
otra posibilidad de mirar la realidad más allá de la medición y la cuantificación; por lo que la autora hace énfasis en el hecho de que detrás de las cifras hay seres humanos. Y en las acciones de los seres humanos, por muy triviales que parezcan, siempre hay significados que las cifras ignoran. La autora cuestiona la concepción que sobre la salud se hace desde las investigaciones clínica y biológica, las cuales también han construido explicaciones monocausales en torno a la enfermedad y la muerte; trabajos como este abren la posibilidad de orientar la mirada de los investigadores hacia un paulatino reconocimiento de otro tipo de condiciones y factores que hacen de la enfermedad y de la muerte acontecimientos de carácter sociocultural, y por lo tanto material de análisis desde otras vertientes del conocimiento científico.

Juan Luis Ramírez Torres es autor del texto "El cuerpo enfermo: metáfora biológica de lo social y lo ético"; en dicho texto el autor aborda el estudio del cuerpo como percepción y metáfora, específicamente trata tres aspectos: los de la carne, la sangre y el espíritu, para lo cual nos remite a algunos datos etnográficos (también de su autoría) del contexto mexicano. Realiza un ejercicio de semiótica del cuerpo, atendiendo el campo psicosomático como una estrategia teórico-conceptual para la comprensión de la enfermedad y la salud, rebasando así la frontera biológica del dolor y la enfermedad. Su estudio se inscribe en la perspectiva del constructivismo y rescata aportaciones de autores como Foucault, Clifford Geertz, Paul Watzlawick y Peter Krieg. El texto es una aportación a la temática que también ha sido trabajada por autores como David Morris y Henri Rubinstein, quienes permiten reflexionar al dolor como una experiencia sociocultural, e insisten en que no se puede continuar con la lógica que considera que existen dos tipos de dolor: dolor físico y dolor del alma; por el contrario se proponen contribuir para que los sujetos entendamos que el dolor humano es uno que se expresa mediante significados, por lo que el dolor no puede reducirse a un problema médico y la medicina del dolor no sólo puede estar en manos de los médicos.

Finalmente, Silvia Ortiz Echániz, a través de su trabajo "Las parteras tradicionales en la ciudad de Chihuahua", expone los resultados de su estudio acerca de las prácticas de una modalidad de la medicina tradicional: la de las parteras, en el sistema local de salud de la capital del estado de Chihuahua. La autora hace un recuento histórico de cómo las parteras fueron integradas al sistema de salud local mediante estrategias de organización y capa- 
citación, pero fundamentalmente rescata desde su contexto sociocultural las interpretaciones, de sí mismas y de la población que asisten, sobre sus experiencias en la medicina tradicional. Dicho estudio es realizado desde la mirada de la antropología médica, que también se interesa por la experiencia de los sujetos, y que en este caso muestra cómo conviven la medicina tradicional y el sistema de salud en un ámbito urbano que a la vez está en parte determinado por la existencia de la industria maquiladora, en esa entidad del norte del país.

\section{Bibliografía}

Rubinstein, Henri (1988), La medicina del dolor, Alianza Editorial, Madrid.

Kübler-Ross, Elizabeth (2002), Sida: el gran desafío, Ediciones Martínez Roca, Barcelona.

Alicia Margarita Tinoco García Universidad Autónoma del Estado de México

Correo-e: atinoco@uaemex.mx 